\title{
30. DATA REPORT: GEOCHEMICAL LOGGING RESULTS FROM THE EASTERN EQUATORIAL PACIFIC: HOLE 504B ${ }^{1}$
}

\author{
Elizabeth Lewis Pratson, ${ }^{2}$ Cristina Broglia, ${ }^{2}$ Philippe Pezard, ${ }^{3}$ and Peter K.H. Harvey ${ }^{4}$
}

\begin{abstract}
Geochemical well logs were obtained through sediment and basalt at Site 504 of Leg 140. Corrections have been applied to the logs to account for variations in borehole size, drilling-fluid composition, and drill-pipe attenuation. Concentrations of Th, U, and Gd, as well as oxide weight percentages, have been calculated from the logs and compared with available X-ray-fluorescence (XRF) core measurements. The geochemical processing was performed in the open hole sections of Hole 504B only. The comparison of XRF core data to log data is good.
\end{abstract}

\section{INTRODUCTION}

The primary objective of Leg 140 was to deepen the previously existing Hole 504B into the sheeted dike complex (Fig. 1) (Shipboard Scientific Party, 1992). The hole was logged with the geochemical logging tool string (GLT), which measures the major elements of a formation at intervals of $0.1524 \mathrm{~m}$. The GLT measurements provide continuous, in-situ chemical measurements of the rock and are not affected by incomplete core recovery or core expansion, a common problem in core-based studies.

This report describes the basic principles of the GLT and outlines the post-cruise processing techniques. It then briefly compares geochemical log values with lithologic core descriptions and available core measurements.

\section{GEOCHEMICAL TOOL STRING}

The geochemical logging tool string (GLT) consists of four tool components: the natural gamma-ray tool (NGT), the compensated neutron tool (CNT), the aluminum activation clay tool (AACT), and the gamma-ray spectrometry tool (GST). (GLT, NGT, CNT, AACT, and GST are trademarks of Schlumberger; Fig. 2.) The combination of the tool components uses three separate modes of gamma-ray spectroscopy for a comprehensive elemental analysis of the formation. The NGT, located at the top of the tool string, measures the naturally occurring radionuclides, thorium (Th), uranium (U), and potassium (K), before the formation is irradiated by the nuclear sources contained in the tools below. The CNT, located below the NGT, carries a low-energy californium-252 $\left({ }^{252} \mathrm{Cf}\right)$ neutron source to activate the $\mathrm{Al}$ atoms in the formation. The AACT, a modified NGT, is located below the ${ }^{252} \mathrm{Cf}$ source, measuring the activated gamma rays in the formation. By combining the AACT measurement with the previous NGT measurement, the background radiation is eliminated, and a reading of formation $\mathrm{Al}$ is obtained (Scott and Smith, 1973). The GST, at the base of the string, carries a pulsed neutron generator to induce prompt-capture gamma-ray reactions in the borehole and formation and a $\mathrm{NaI}(\mathrm{Tl})$ scintillation detector to measure the energy spectrum of gamma rays generated by the neutron capture reactions. Because each of the elements in the formation is characterized by a unique spectral signature,

\footnotetext{
'Erzinger, J., Becker, K., Dick, H.J.B., and Stokking, L.B. (Eds.), 1995. Proc. ODP. Sci. Results, 137/140: College Station, TX (Ocean Drilling Program).

${ }^{2}$ Borehole Research Group, Lamont-Doherty Earth Observatory of Columbia University, Palisades, NY 10964, U.S.A.

${ }^{3}$ Institut Méditerranéen de Technologie. Technopole de Chateau-Gombert, 13451 Marseille Cedex 13, France.

${ }^{4}$ Borehole Research, Department of Geology, University of Leicester, Leicester LEI 7RH, United Kingdom.
}

it is possible to derive the contribution (or yield) of each of the major elements silicon $(\mathrm{Si})$, iron $(\mathrm{Fe})$, calcium $(\mathrm{Ca})$, titanium $(\mathrm{Ti})$, sulfur $(\mathrm{S})$, gadolinium (Gd), and potassium (K) from the measured spectrum, and then, in turn, to estimate the relative abundance in the formation of each element above by combining with the elemental concentrations from the NGT and AACT. The GST also measures the hydrogen $(\mathrm{H})$ and chlorine $(\mathrm{Cl})$ in the borehole and formation, but these elements are not used for determining rock geochemistry.

The only major rock-forming elements not measured by the GST are magnesium $(\mathrm{Mg}$ ) and sodium $(\mathrm{Na})$; the neutron-capture cross sections of these elements are too small relative to their typical abundance to be detected by the GST. A rough estimate of $\mathrm{Mg}+\mathrm{Na}$ can be made by using the photoelectric factor (PEF), measured by the lithodensity tool. This measured PEF is compared with a calculated PEF (a summation of the PEF from all of the measured elements). The separation between the measured and calculated PEF is, in theory, attributable to any element left over in the formation (i.e., $\mathrm{Mg}$ and $\mathrm{Na}$ ). Further explanation of this technique is found in Hertzog et al. (1989). The $\mathrm{Mg}$ calculation was not attempted for this leg because including it in the normalization with the other elements induces noise into all other elements, which proves to be erroneous in Ocean Drilling Program (ODP) wells (Pratson et al., in press). $\mathrm{MgO}+\mathrm{Na}_{2} \mathrm{O}$ values from core data are included in the normalization step of the processing. This is explained further in Step 5 of the following data-reduction section.

\section{DATA REDUCTION}

The well-log data from the Schlumberger tools are transmitted digitally up a wire line and are recorded and processed on the JOIDES Resolution in the Schlumberger Cyber Service Unit (CSU). The results from the CSU are made available as "field logs" for initial, shipboard interpretation. Subsequent reprocessing is necessary to correct the data for the effects of fluids added to the well, logging speed, and drill-pipe interference. Processing of the spectrometry data is required to transform the relative elemental yields into oxide weight fractions. The processing is performed with a set of log-interpretation programs written by Schlumberger that were modified to account for the lithologies and hole conditions encountered in ODP holes. The steps are summarized as follows:

\section{Reconstruction of Relative Elemental Yields from Recorded Spectral Data}

This first processing step compares the measured spectra from the gamma-ray spectrometry tool with a series of "standard" spectra to determine the relative contribution (or yield) of each element. Each "standard" approximates the spectrum of each element and is com- 


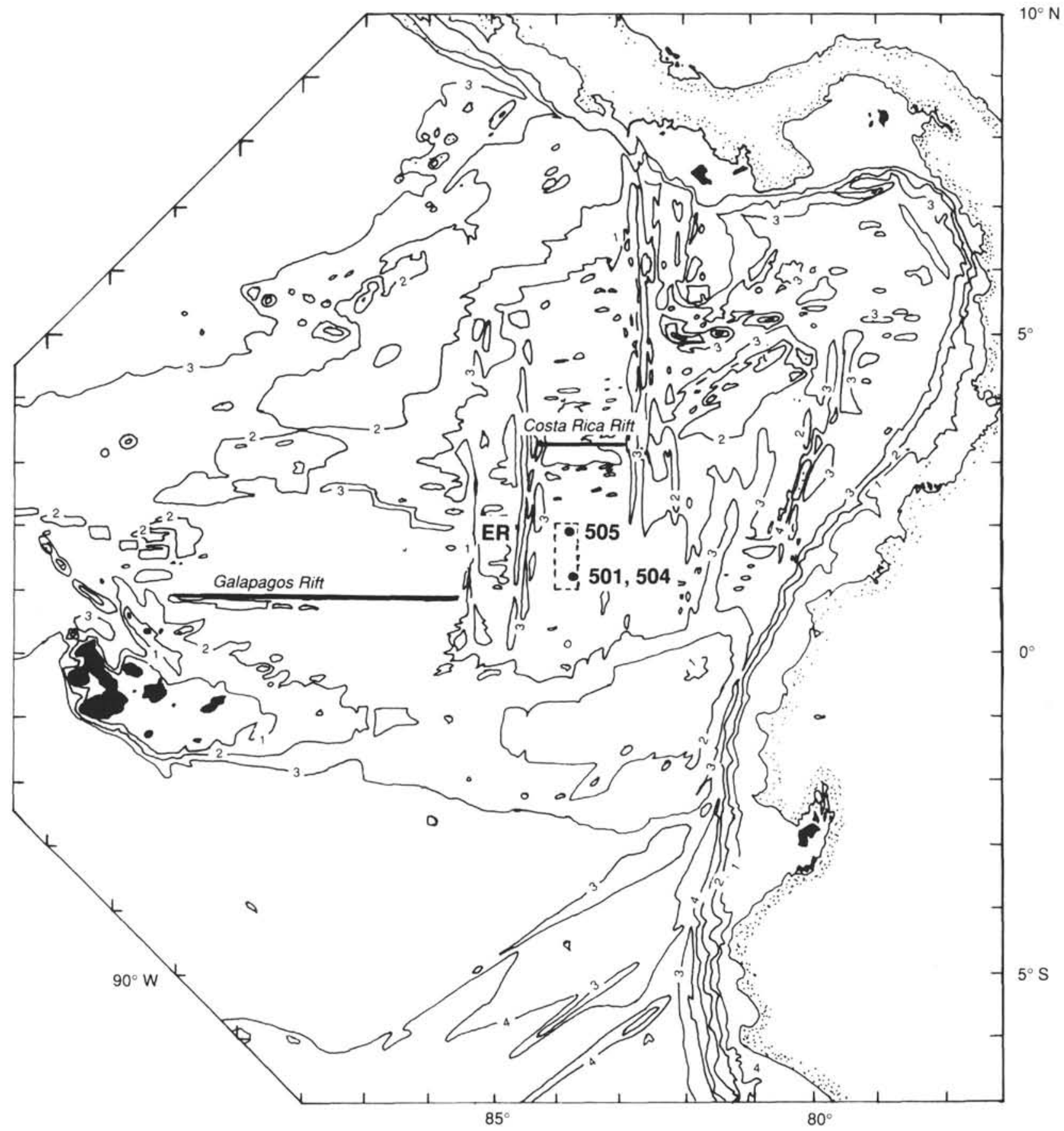

Figure 1. Location of DSDP/ODP Sites 501, 504, and 505 south of the Costa Rica Rift in the eastern equatorial Pacific Ocean, from Hobart et al. (1985). E.R. = Ecuador Rift.

bined at each depth with the recorded spectrum in a weighted, leastsquares inversion to determine the relative elemental yields.

Six elemental standards ( $\mathrm{Si}, \mathrm{Fe}, \mathrm{Ca}, \mathrm{S}, \mathrm{Cl}$, and $\mathrm{H}$ ) are used to produce the shipboard yields, but three additional standards (Ti, Gd, and $\mathrm{K})$ can be included in the post-cruise processing to improve the fit of the spectral standards to the measured spectra (Grau and Schweitzer, 1989). Although $\mathrm{Ti}, \mathrm{Gd}$, and $\mathrm{K}$ often appear in the formation in very low concentrations, they can make a large contribution to the measured spectra because they have large neutron-capture cross sections. For example, the capture cross section of Gd is 49,000 barns, whereas that of $\mathrm{Si}$ is 0.16 barns (Hertzog et al., 1989). Therefore, including Gd is necessary when calculating the best fit of the standard spectra to the measured spectra.

The spectral analysis was performed using the spectral standards for $\mathrm{H}, \mathrm{Si}, \mathrm{Ca}, \mathrm{Cl}, \mathrm{Fe}, \mathrm{Ti}$, and $\mathrm{Gd}$. The spectral standards for $\mathrm{S}$ and $\mathrm{K}$ were not used, because these elements exist in concentrations below the resolution of the tool, and because the inclusion of $\mathrm{S}$ and $\mathrm{K}$ was found to significantly increase the noise level of all the other yields. A straight, five-point $(2.5 \mathrm{ft}, 0.762 \mathrm{~m})$ smoothing filter was applied to all the yields to reduce the noise in the data during this reconstruction step. An additional 10 point $(5 \mathrm{ft}, 1.523 \mathrm{~m})$ smoothing filter was applied to the hole to further reduce the noise level in the normaliza- 
TCCB

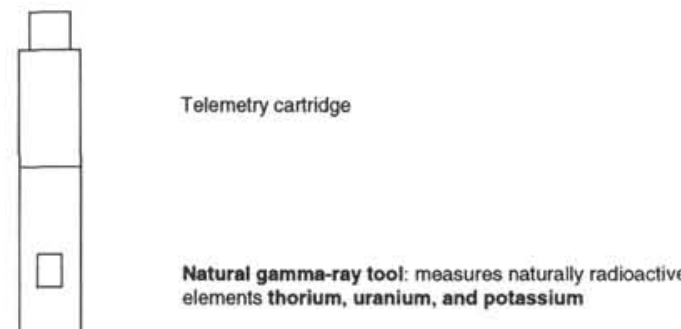

NGT

CNT-G

AACT

GST

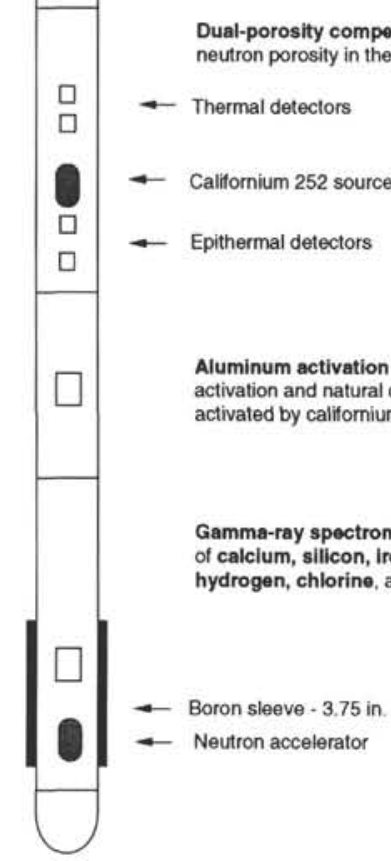

Figure 2. Schematic drawing of the Schlumberger geochemical logging tool string used in the Ocean Drilling Program.

tion factor (explained in Step 5), which affects the overall character of the final elemental yields.

\section{Depth Shifting}

Geochemical processing involves the integration of data from the different tool strings; consequently, it is important that all the data are depth correlated to one reference logging run. The NGT, run on each of the logging tool strings, provides a spectral gamma-ray curve with which to correlate each of the logging runs. A reference run is chosen on the basis of low cable tension (the logging run with the least amount of cable sticking) and high cable speed (tools run at faster speeds are less likely to stick and are less susceptible to data degradation caused by ship heave). The depth-shifting procedure involves selecting several reference points where log characters are similar and then invoking a program that stretches or squeezes sections of the matching logging run to fit the reference logging run. The Leg 111 data were used as the depth reference for this hole.

\section{Calculation of Total Radioactivity and Th, $U$, and $K$ Concentrations}

The third processing routine calculates the total natural gamma radiation in the formation, as well as concentrations of Th, $\mathrm{U}$, and $\mathrm{K}$, using the counts in five spectral windows from the natural gamma-ray tool (Lock and Hoyer, 1971). This routine resembles shipboard processing; however, the results are improved during post-cruise processing by including corrections for hole-size changes and temperature variations. A Kalman filtering (Ruckebusch, 1983) is used in the CSU processing at sea to minimize the statistical uncertainties in the logs, which can otherwise create erroneous negative values and anti-correlation (especially between Th and U). An alpha filter has been introduced more recently and is now recommended by Schlumberger for shore-based processing. This filter strongly smooths the raw spectral counts but keeps the total gamma-ray curve unsmoothed before calculating the Th, U, and K (C. Flaum, pers. comm., 1988). The outputs of this program are $\mathrm{K}$ (wet wt\%), $\mathrm{U}(\mathrm{ppm})$, and Th (ppm), as well as total gamma-ray and computed gamma-ray (total gamma ray minus U contribution) curves.

\section{Calculation of Al Concentration}

The fourth processing routine calculates the concentration of $\mathrm{Al}$ in the formation using four energy windows recorded with the AACT. During this step, corrections are made for natural radioactivity, borehole-fluid neutron-capture cross section, formation neutron-capture cross section, formation slowing-down length, and borehole size. Porosity and density logs are needed to convert the wet-weight percentages of $\mathrm{K}$ and $\mathrm{Al}$ curves to dry-weight percentages. Because no direct porosity or density logs were recorded, these curves were created from interpolated core points and then grossly smoothed to eliminate noise.

A correction also is made for $\mathrm{Si}$ interference with $\mathrm{Al}$; the ${ }^{252} \mathrm{Cf}$ source activates the $\mathrm{Si}$, producing the aluminum isotope ${ }^{28} \mathrm{Al}$ (Hertzog et al., 1989). The program uses the Si yield from the gamma-ray spectrometry tool to determine the $\mathrm{Si}$ background correction. The program calculates dry-weight percentages of $\mathrm{Al}$ and $\mathrm{K}$, which are used in the calculation and normalization of the remaining elements.

\section{Normalization of Elemental Yields from the GST to Calculate the Elemental Weight Fractions}

Relative concentrations of the GST-derived elemental yields can be determined by dividing each elemental yield by a relative spectral sensitivity factor $S_{i}$. These factors are constants, which can be measured in the laboratory and are principally related to the thermal neutroncapture cross sections and the gamma-ray production and detection probabilities of the element (Hertzog et al., 1989). The relative elemental concentrations are related to the desired absolute concentrations by a depth-dependent normalization factor $F$, as defined by the relationship:

$$
W t_{i}=F Y_{i} / S_{i}
$$

where:

$$
\begin{aligned}
& W t_{i}=\text { absolute elemental concentration, } \\
& Y_{i}=\text { relative elemental yield, } \\
& S_{i}=\text { relative spectral sensitivity factor, and } \\
& F=\text { depth-dependent normalization factor. }
\end{aligned}
$$

The normalization factor is calculated based on the assumption that the sum of all the elemental weight fractions is $100 \%$. The closure model accounts for carbon and oxygen, which are not measured by this tool string, by approximating their amounts in combination with each of the measurable elements as a single carbonate or oxide factor. The dry-weight percentages of $\mathrm{Al}$ and $\mathrm{K}$ are normalized with the reconstructed elemental yields to determine $F$ at each depth interval with the following equation:

$$
F\left(\sum_{i} X_{i} Y_{i} / S_{i}\right)+X_{K} W t_{K}+X_{A l} W t_{A l}=100
$$

where:

$X_{i}=$ oxide factor: atomic wt of oxide or carbonate $\div$ atomic wt of element $i$,

$X_{K}=$ oxide factor of $\mathrm{K}$ : atomic wt of oxide of element $\mathrm{K} \div$ atomic wt of $\mathrm{K}$, 
Table 1. Oxide factors used in normalizing elements to $100 \%$ and converting elements to oxides.

\begin{tabular}{ccc}
\hline Element & Oxide/carbonate & $\begin{array}{c}\text { Conversion } \\
\text { factor }\end{array}$ \\
\hline $\mathrm{Si}$ & $\mathrm{SiO}_{2}$ & 2.139 \\
$\mathrm{Ca}$ & $\mathrm{CaO}$ & 1.399 \\
$\mathrm{Fe}$ & $\mathrm{Fe}_{2} \mathrm{O}_{3}$ & 1.43 \\
$\mathrm{~K}$ & $\mathrm{~K}_{2} \mathrm{O}$ & 1.205 \\
$\mathrm{Ti}$ & $\mathrm{TiO}_{2}$ & 1.668 \\
$\mathrm{Al}$ & $\mathrm{Al}_{2} \mathrm{O}_{3}$ & 1.889 \\
& & \\
\hline
\end{tabular}

$W t_{K}=$ dry-weight percentage of $\mathrm{K}$, measured from NGT,

$X_{A l}=$ oxide factor of $\mathrm{Al}$ : atomic $\mathrm{wt}$ of oxide of element $\mathrm{Al} \div$ atomic wt of $\mathrm{Al}$, and

$W t_{A l}=$ dry-weight percentage of $\mathrm{Al}$, measured from the AACT

The value $X_{i}$ accounts for the $\mathrm{C}$ and $\mathrm{O}$ associated with each element. Table 1 lists the oxide factors used in this calculation.

The $\mathrm{Mg}$ - and Na-content curves cannot be calculated from the logs, because the neutron-capture cross sections of these elements are too small relative to their typical abundance for detection by the tool string; therefore, available core information is included. A constant value of $10.5 \% \mathrm{MgO}+\mathrm{Na}_{2} \mathrm{O}+\mathrm{MnO}$ was used in the normalization of Hole 504B. This value was derived from the average measured core values.

\section{Calculation of Oxide Percentages}

The final routine converts the elemental weight percentages into oxide/carbonate percentages by multiplying each by its associated oxide factor, as shown in Table 1.

\section{Calculation of Error Logs}

The calculated statistical uncertainty of each element is calculated from each of the elements measured with the GST and NGT (Grau et al., 1990; Schweitzer et al., 1988). This error is strongly related to the normalization factor, which is calculated at each depth (Eq. 2). The normalization factor is displayed to the right of the logs. A lower normalization factor represents better counting statistics and higher quality data.

\section{COMPARISON OF GEOCHEMICAL LOGS TO CORE AT HOLE 504B}

The processed natural gamma-ray curves at Hole 504B, shown in Figure 3, are displayed adjacent to a core-recovery column. The pro- cessed NGT curves are from the geochemical logging tool string. Figure 4 displays the oxide-weight fractions estimated from the logs at Hole 504B, along with calculated statistical uncertainties of each element (Grau et al., 1990; Schweitzer et al., 1988). Available core measurements of XRF major elemental analyses are displayed as solid circles for comparison with the oxide-weight fractions derived from the log data.

\section{REFERENCES*}

Grau, J.A., and Schweitzer, J.S., 1989. Elemental concentrations from thermal neutron capture gamma-ray spectra in geological formations. Nucl. Geophys., 3:1-9.

Grau, J.A., Schweitzer, J.S., and Hertzog, R.C., 1990. Statistical uncertainties of elemental concentrations extracted from neutron induced gamma-ray measurements. IEEE Trans. Nucl. Sci., 37:2175-2178.

Hertzog, R., Colson, L., Seeman, B., O’Brien, M., Scott, H., McKeon, D., Wraight, J., Grau, J., Ellis, D., Schweitzer, J., and Herron, M., 1989. Geochemical logging with spectrometry tools. SPE Form. Eval., 4:153-162.

Hobart, M.A., Langseth, M.G., and Anderson, R.N., 1985. A geothermal and geophysical survey on the south flank of the Costa Rica Rift: Sites 504 and 505. In Anderson, R.N., Honnorez, J., et al., Init. Repts. DSDP, 83: Washington (U.S. Govt. Printing Office), 379-404.

Lock, G.A., and Hoyer, W.A., 1971. Natural gamma-ray spectral logging. Log Analyst, 12:3-9.

Pratson, E.L., Broglia, C., and Jarrard, R., in press. Data report: geochemical well logs through Cenozoic and Quaternary sediments from Sites 815,817, 820, 822, and 823. In McKenzie, J.A., Davies, P.J., Palmer-Julson, A., et al., Proc. ODP, Sci. Results, 133: College Station, TX (Ocean Drilling Program).

Ruckebusch, G., 1983. A Kalman filtering approach to natural gamma ray spectroscopy in well logging. IEEE Trans. Autom. Control, AC-28:372-380.

Schweitzer, J.S., Grau, J.A., and Hertzog, R.C., 1988. Precision and accuracy of short-lived activation measurements for in situ geological analyses. J. Trace Microprobe Techn., 6:437-451.

Scott, H.D., and Smith, M.P., 1973. The aluminum activation log. Log Analyst, 14:3-12.

Shipboard Scientific Party, 1992. Site 504. In Dick, H.J.B., Erzinger, J., Stokking, L.B., et al., Proc. ODP, Init. Repts., 140: College Station, TX (Ocean Drilling Program), 37-200.

"Abbreviations for names of organizations and publications in ODP reference lists follow the style given in Chemical Abstracts Service Source Index (published by American Chemical Society).

Date of initial receipt: 29 March 1993

Date of acceptance: 13 July 1993

Ms 137/140SR-042 

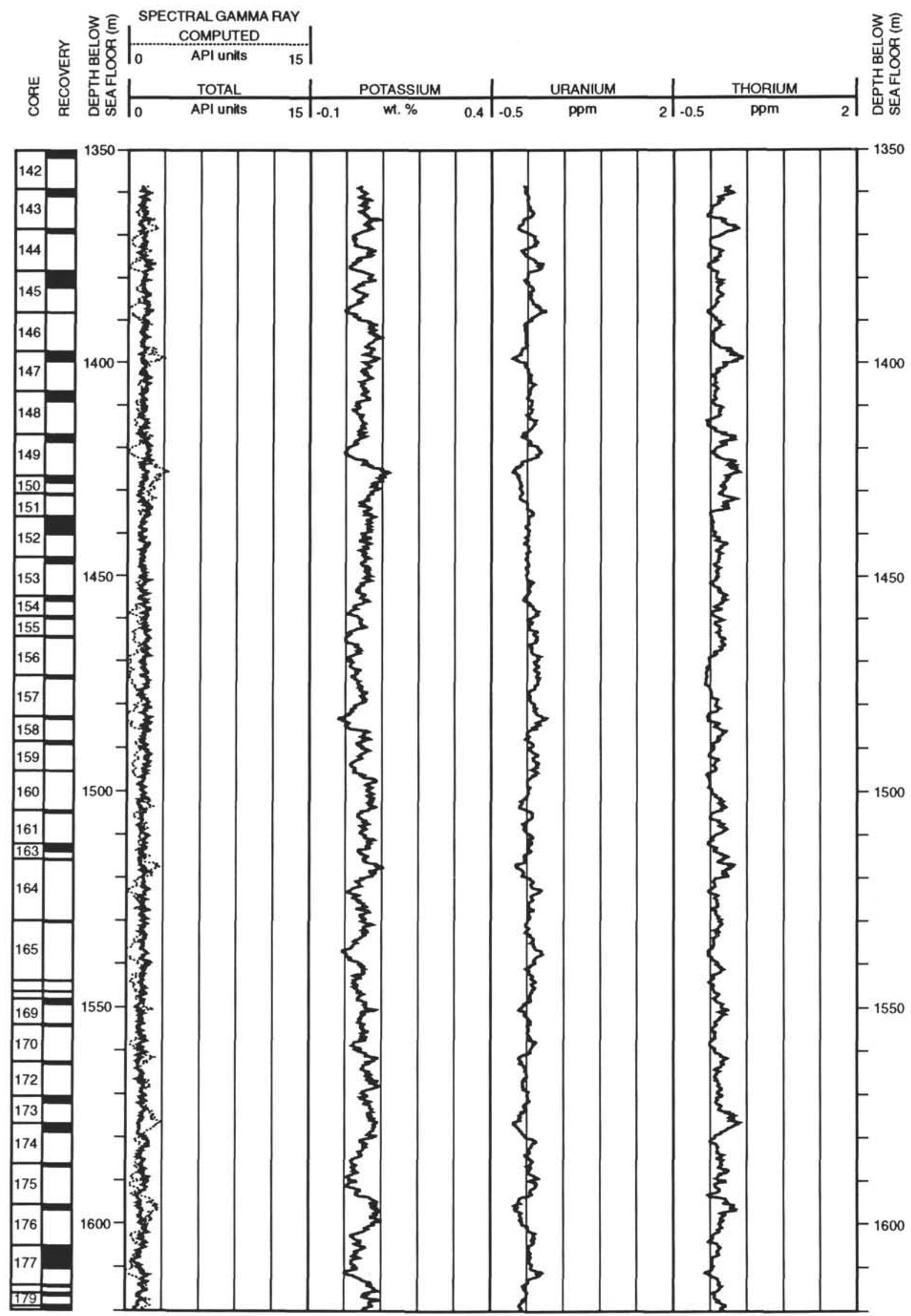

Figure 3. Processed natural gamma-ray data, Hole 504B. 

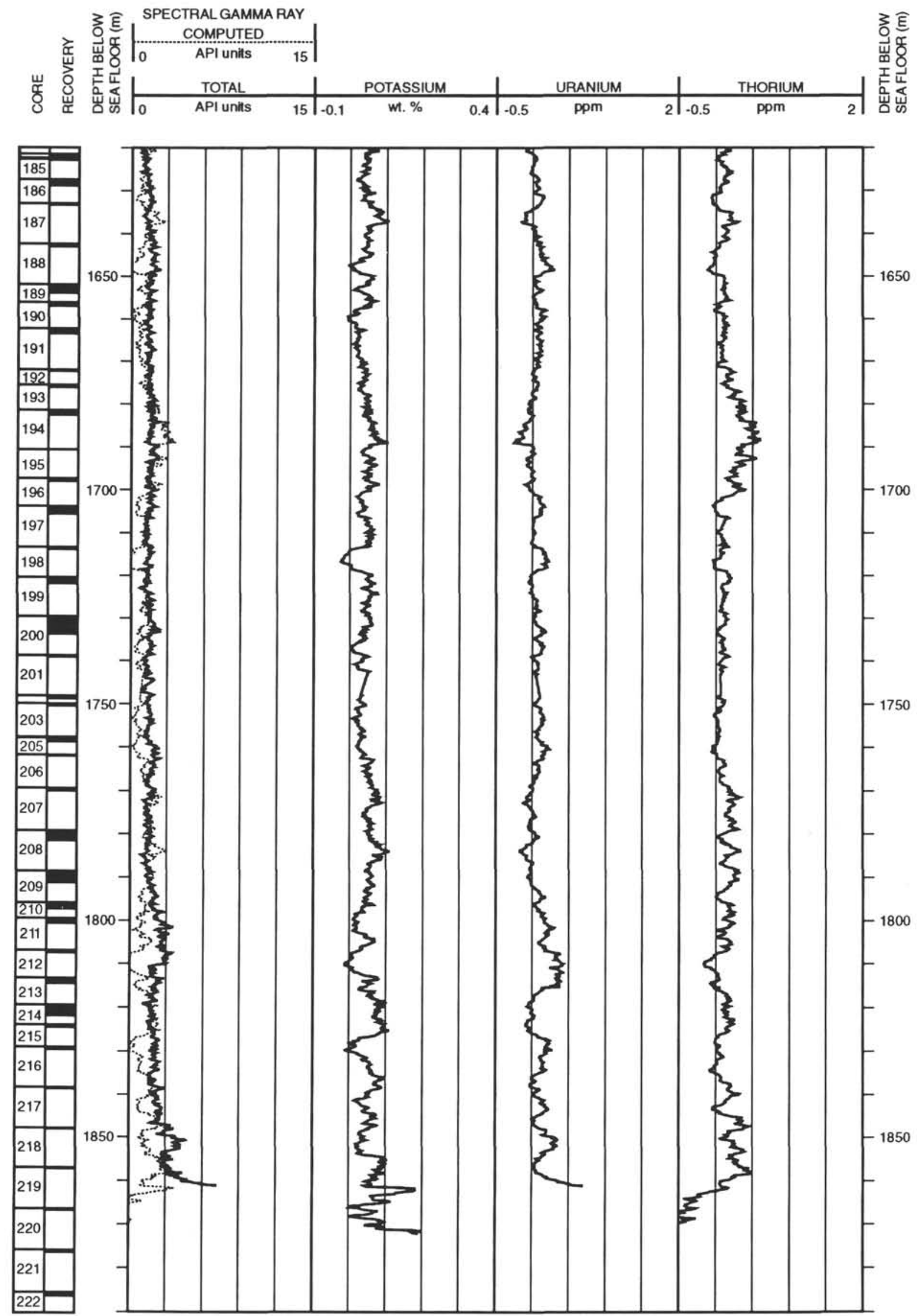

Figure 3 (continued). 


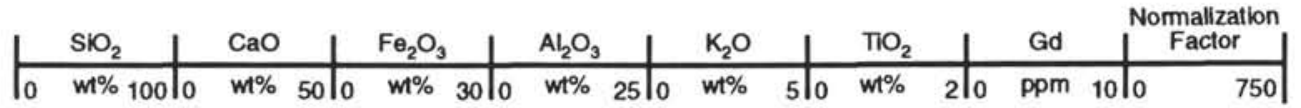

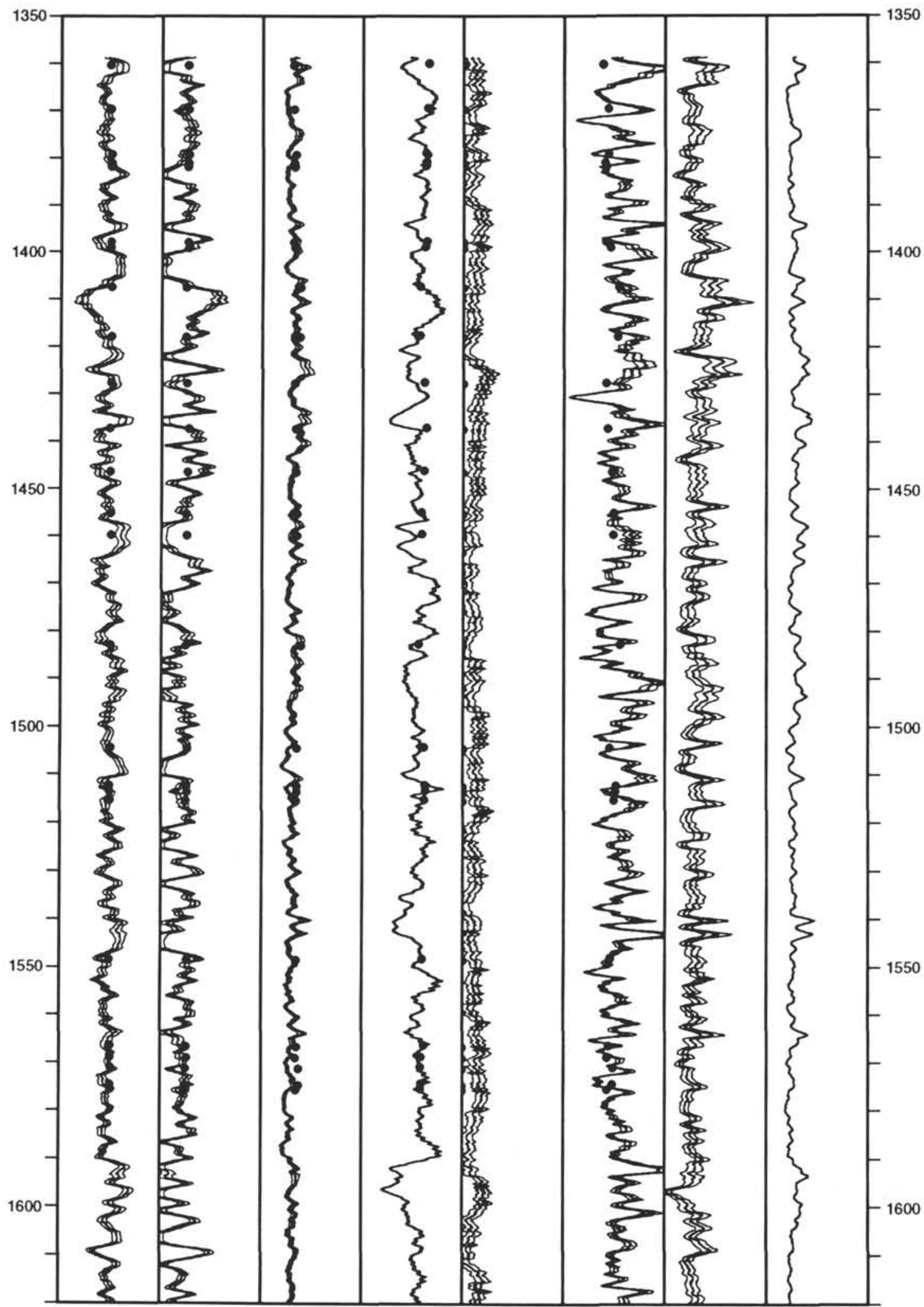

Figure 4. Estimates of major oxide-weight fractions from geochemical logs, Hole 504B. Solid circles represent XRF measurements (Shipboard Scientific Party, 1992). 

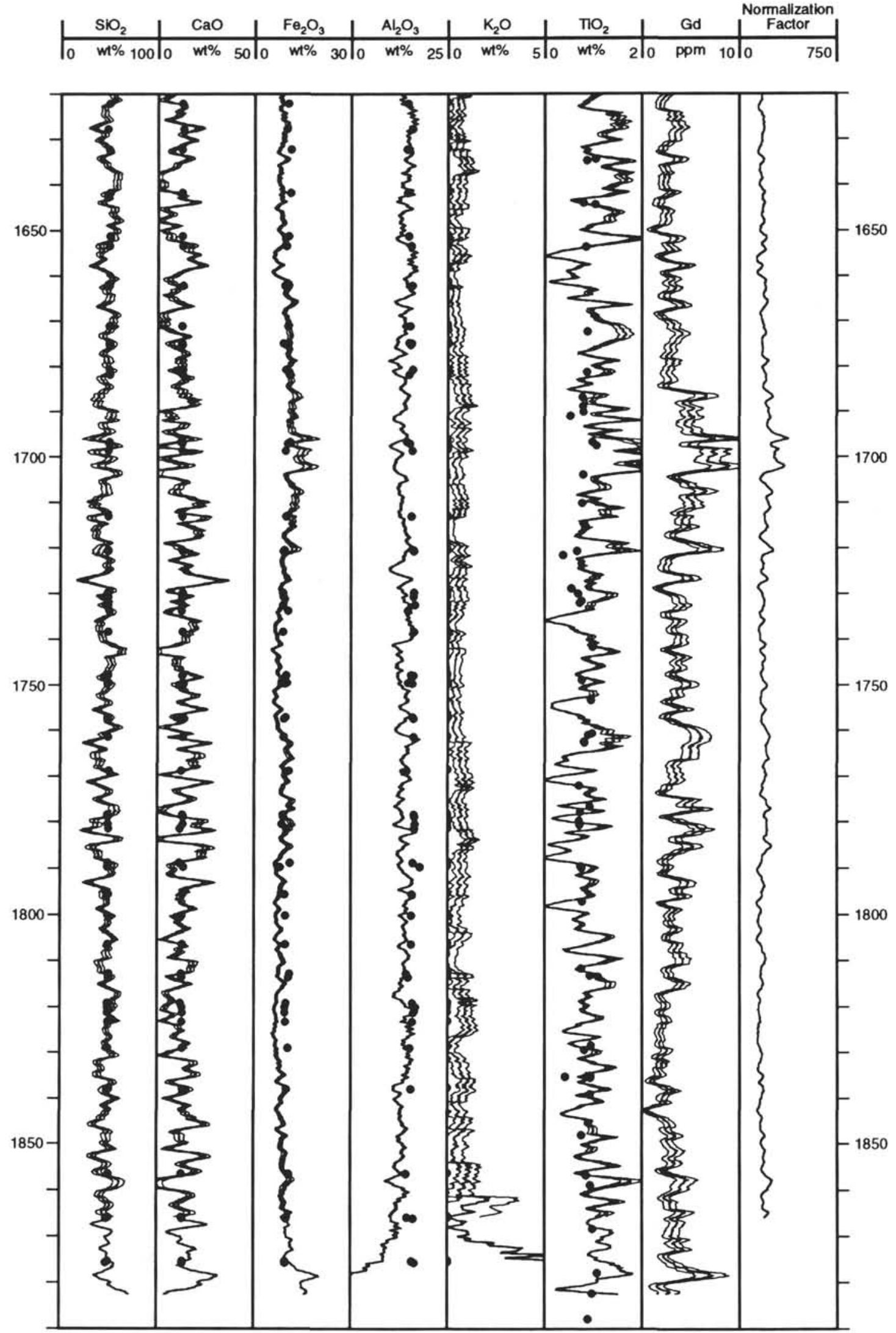

Figure 4 (continued). 